\title{
Comparisons on Calculating Methods of Total Daily Global Solar Radiation in Urban Area Based on Panoramic Images
}

\author{
Moyan Zhang ${ }^{1,2}$, Yan $\mathrm{Liu}^{1,2^{*}}$, Ruixin Chen ${ }^{1,2}$, Xiangfei Guo ${ }^{1,2}$, Weiqing Yuan ${ }^{1,2}$, and Liu Yang ${ }^{1,2}$ \\ ${ }^{1}$ State Key Laboratory of Green Building in Western China, 710055, Xi'an P.R. China \\ ${ }^{2}$ School of Architecture, Xi' an University of Architecture and Technology, 710055, Xi' an, Shaanxi P.R. China
}

\begin{abstract}
In this paper, the total daily global solar radiation is tested at 18 locations with different morphological characteristics in Xi' an University of Architecture and Technology. PTgui is used to convert the panoramic pictures from Baidu Street Map to fisheye images. Sky view factor (SVF) and tree view factor (TVF) are calculated by Rayman model with fisheye images. SVF is used to calculate the total daily global solar radiation at the 18 locations with two different methods and TVF is used to classify the locations. The calculations and testing results are compared and combined the morphological characteristics. Then it is found that using suitable methods on different locations is necessary to obtain more accurate results whether the TVF (tree view factor) is more than 0.3 or less. To obtain solar radiation at different locations in the urban area, the calculating methods should be carefully chosen based on the morphology characteristics of the location.
\end{abstract}

\section{Introduction}

Solar radiation is the main driving force of surface thermal energy balance and plays an important role in regulating urban micro-climate [1]. Urban outdoor thermal comfort and human health are also closely related to urban solar radiation $[2,3]$. Investigating the patterns of solar radiation in urban area can help design urban reasonably, which can also handle the existing urban environmental problems and make a prevention of future problems in advance.

Urban morphology is an important element impacting the micro-climate of urban area including distribution of solar radiation [4]. Many researches were conducted to figure out the relationship between urban morphology characteristics and outdoor thermal comfort [5- 10]. In this filed, height to width ratio $(\mathrm{H} / \mathrm{W})$ and Sky View Factor (SVF) are among the most researched urban morphological parameters in recent years [8-10]. SVF is the ratio of radiation received by a planar surface from the sky area to the radiation from the whole hemispheric radiating environment [11]. SVF reflects the shade degree of the sky blocked by surrounding obstructions, and it is usually represented by a dimensionless value between 0 and 1 , where 1 indicates there is no obstructions around and 0 indicates the sky is fully shaded by obstructions [12]. Perez et al. [13] suggested a positive linear correlation between the isotropic diffuse solar radiation and SVF.

Since Oke [14] suggested that SVF is one of the most important indexes of urban heat island effect, many researches were conducted to calculate SVF and reveal SVF affecting urban thermal environment including solar radiation. Calculating SVF is always based on fisheye images of the testing locations or building 3D models [1527]. Fisheye images can be gathered by taking photos or converting street panorama photos provided by street map providers such as Google or Baidu [15-22]. 3D building model information can be gained from digital elevation model (DEM) provided by remote sensing data or LiDAR data [23-25]. The original way to calculate SVF is to take pictures through fish-eye lens, and then identify the pictures to calculate the SVF manually [26]. With newly technologies, many software can help identify the pictures and calculate the SVF automatically, such as Rayman model, which can also calculate the condition of outdoor thermal comfort (such as PET) [20, 21]. Zeng et al. [15] presented a method of estimating SVF by directly using panoramas from Baidu Street Map without converting the panorama into fish-eye image and the accuracy of this method is verified. Gál et al. [23] used two methods, high resolution 3D urban raster and vector databases, to calculate SVF, and proved they are both shown to be powerful tools to obtain a general picture of the geometrical conditions of an urban environment. Hämmerle et al. [27] compared the result of four different software and models (ArcView, Rayman, BMSKyView, SkyHelios, and SOLWEIG) estimating SVF under the same condition, and the results showed highly consistency after the same weighting was applied to the sky obstacles. Besides the methods of calculating SVF, the patterns of SVF effect outdoor thermal environment were also investigated a lot. Through taking fisheye photos, Hwang et al. [22] researched the relationship between SVF and human thermal comfort in the business district with highdensity and high-rise buildings, finding that SVF has different impact on outdoor thermal comfort and human

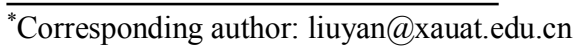


behaviours in different seasons. In high density urban environment, the spatiotemporal patterns of street-level solar radiation were investigated by estimating SVF with fisheye images converted form panoramas provided by Google Street Map, resulting the direction of street has a noticeable influence on solar radiation intensity $[16,17]$. Li et al. $[18,19]$ studied the patterns of the distribution of SVF and shade affecting solar radiation and outdoor thermal comfort in street canyon by identifying and analysing the integral part of the fisheye images converted from google street panoramas. They suggested that using tree view factor (TVF), a ratio of radiation blocked by tree from the sky area to the radiation from the whole hemispheric radiating environment, to evaluate the proportion of trees in the sky. And they also present a method to estimate total daily solar radiation with SVF.

According to recent studies, there are two main calculating methods based on SVF to estimate the total daily global solar radiation of the testing locations. One is presented by Matzarakis and applied in Rayman model [20]. This method requires all-day hourly solar radiation data or other weather data such as local cloud cover. Since Chinese meteorological stations cannot provide cloud cover data and there are only a few cities has hourly solar radiation data, this method can only be used in a few cities in China. The other one is presented by $\mathrm{Li}$ [18]. This method only requires total daily direct and diffuse solar radiation data. Many researchers use one of these two methods to estimate the solar radiation to study the outdoor thermal comfort, but few of them try to find out the applicability of these two methods.

In this study, 18 locations representing different conditions of urban street morphology characteristics are chosen to perform the field experiment of total daily global solar radiation. Then the panoramas of these 18 locations are gained from Baidu Street Map to calculate total daily global solar radiation with upon two methods respectively. The testing results and calculations are compared to find out the applicability of these two methods. And TVF is used to classify the locations. Additionally, the patterns of street features affecting the relationship between SVF and solar radiation are researched preliminarily.

\section{Study area and data}

\subsection{Study area}

The field experiment is conducted in $\mathrm{Xi}$ 'an, because the solar radiation observation station in Xi' an University of Architecture and Technology can provide hourly solar radiation data. The testing locations are chosen in School of Architecture, Xi'an University of Architecture and Technology. Because the Baidu Street Map covers the school and it is convenient to test solar radiation all day at the middle of streets in school instead of the streets outside full of cars (Fig. 1).

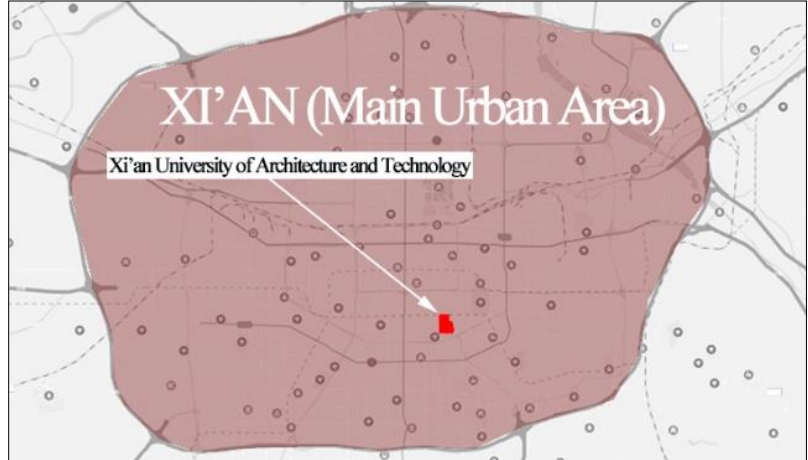

Fig. 1. Study area (Xi' an University of Architecture and Technology)

\subsection{Meteorological data}

The meteorological data in this paper are provided by the solar radiation observation station located on the roof with fifth floor (about $15 \mathrm{~m}$ high) of a building in Xi'an University of Architecture and Technology. The surrounding environment of the observation station meet the requirement of no shade. This station use pyrheliometer with instrument model of LP PYRA03 made by Delta Ohm in Italia to test solar radiation (Fig. 2 ). This pyrheliometer can accurately measure surface solar radiation (Spectral range: $0.3 \mu \mathrm{m}-3 \mu \mathrm{m}$ ) with the response time $(95 \%)$ less than 30 s and instability (annual variation) $\pm 2.5 \%$. This instrument can provide halfhourly direct and diffuse solar radiation data, including average value and momentary value. The average value is the mean of every minute value in every half-hour, and the momentary value is the record on every half-hour. This paper takes the average values and processes them to hourly data to investigate.

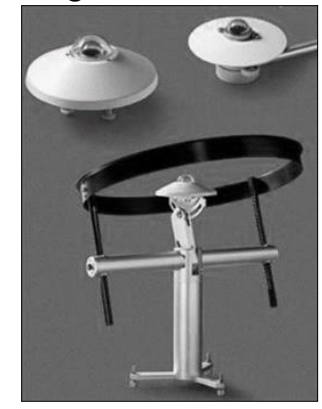

Fig. 2. Delta Pyrheliometer LP PYRA03

\subsection{Image data}

The panoramas took in this paper are provided by Baidu Street Map [28]. Among the 18 locations, every location has a panorama image, which is converted to fisheye image through PTgui software, then identified in Rayman model half-manually.

\section{Methodology}

\subsection{The field experiment}


In order to consider if the different morphological characteristics have the different effects on calculation accuracy, this study choose 18 locations with different morphological characteristics in the School of Architecture, Xi'an University of Architecture and Technology (Fig. 3). The locations tested contain the different conditions including $\mathrm{SVF}<0.2, \mathrm{SVF}>0.8$, the south-north street with less and more tree shade, the eastwest street with less and more tree shade, the crossroads, the corners and the junctions of three roads. Since the calculations of SVF and TVF are decided by the condition of the location where the panorama photos are taken, the result of solar radiation calculated with SVF is also affected by the condition of the location, so is the testing result. Therefore, the locations must have the same form as where the panorama photos are taken. The testing locations are carefully chosen compared with the panorama photos provided by Baidu Street Map.

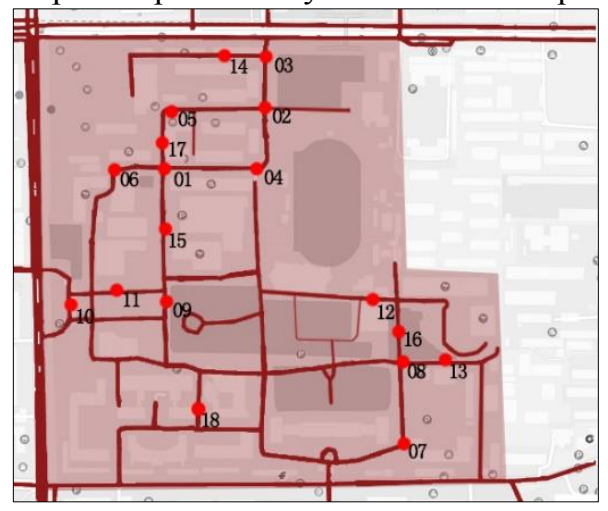

Fig. 3. Testing locations in Xi' an University of Architecture and Technology

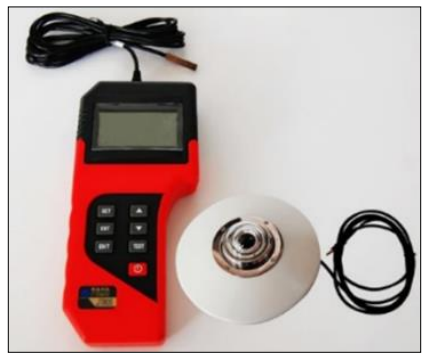

Fig. 4. JTR05 Hand-held solar radiation detector

The testing instrument is JTR05 Hand-held solar radiation detector (Fig. 4), produced by Beijing Jiantong Technology. The response time (95\%) is less than $35 \mathrm{~s}$ and instability (annual variation) is $\pm 2 \%$. This instrument can record minutely global solar radiation automatically. The minutely data is averaged every hour.

Since the instrument can only be used in sunny day, the testing date is August $1^{\text {th }}, 2^{\text {th }}$ and $4^{\text {th }}$ in 2019. Six locations are tested everyday, because the limitation of the number of instruments. The testing starts at 7:30 am and ends up at 7:30 pm, because no matter before or after this period, the solar radiation is too low to detect.

\subsection{Calculating sky view factor (SVF) and tree view factor (TVF)}

SVF and TVF both can reflect the morphology characteristics of locations. They have the same calculating principle except SVF is used to describe the weight of sky area and TVF describes the weight of tree area in the whole hemispheric radiating environment. In this paper, SVF and TVF are both calculated in Rayman model (Table 1.). The module in Rayman to calculate SVF can also calculate TVF, as long as the sky area is replaced with tree area manually.

Table 1. Locations with SVF and TVF

\begin{tabular}{|c|c|c|c|}
\hline NO. & 01 & 02 & 03 \\
\hline SVF & 0.330 & 0.367 & 0.574 \\
\hline TVF & 0.464 & 0.509 & 0.396 \\
\hline \multicolumn{4}{|l|}{ Image } \\
\hline NO. & 04 & 05 & 06 \\
\hline SVF & 0.367 & 0.510 & 0.317 \\
\hline TVF & 0.562 & 0.144 & 0.274 \\
\hline \multicolumn{4}{|l|}{ Image } \\
\hline NO. & 07 & 08 & 09 \\
\hline SVF & 0.069 & 0.043 & 0.859 \\
\hline TVF & 0.762 & 0.924 & 0.081 \\
\hline \multicolumn{4}{|l|}{ Image } \\
\hline NO. & 10 & 11 & 12 \\
\hline SVF & 0.807 & 0.486 & 0.237 \\
\hline TVF & 0.012 & 0.429 & 0.499 \\
\hline \multicolumn{4}{|l|}{ Image } \\
\hline NO. & 13 & 14 & 15 \\
\hline SVF & 0.659 & 0.251 & 0.453 \\
\hline TVF & 0.112 & 0.002 & 0.461 \\
\hline \multicolumn{4}{|l|}{ Image } \\
\hline NO. & 16 & 17 & 18 \\
\hline SVF & 0.397 & 0.444 & 0.432 \\
\hline TVF & 0.563 & 0.137 & 0.102 \\
\hline
\end{tabular}




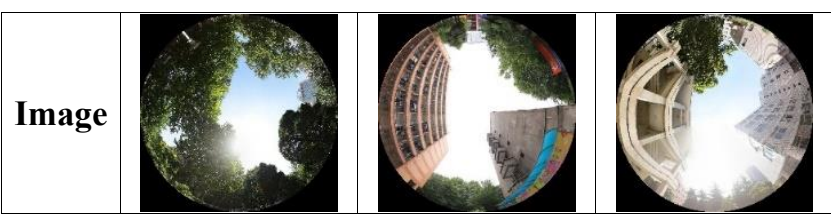

\subsection{Calculating global solar radiation}

\subsubsection{The method-one}

According to Matzarakis' method, the hourly data of solar radiation is required.

The global solar radiation can be divided into direct and diffuse solar radiation:

$$
G_{\mathrm{h}}=I_{\mathrm{h}}+D_{\mathrm{h}}
$$

where $G_{\mathrm{h}}$ is global solar radiation at time $\mathrm{h}$ in one day; $I_{\mathrm{h}}$ is direct solar radiation at time $\mathrm{h}$ in one day; $D_{\mathrm{h}}$ is diffuse solar radiation at time $h$ in one day.

SVF has different effects on direct and diffuse solar radiation. Direct solar radiation is calculated with following equation:

$$
I_{\mathrm{h}}=I_{0 \_\mathrm{h}} \times f_{\mathrm{h}}
$$

where $I_{0_{-}}$is the direct solar radiation at time $\mathrm{h}$ when there is no obstruction around, and data is provided by the observation station; $f_{h}$ is the binary index to indicate whether the sun is blocked or not at time $\mathrm{h}$; if blocked, the $f_{h}$ equals 0 , or the $f_{h}$ equals 1 .

Diffuse solar radiation is calculated with following equation:

$$
D_{\mathrm{h}}=D_{\text {iso_h }} \times \Psi_{\text {svf }}+D_{\text {aniso_h }} \times f_{\mathrm{h}}
$$

where $D_{\text {iso_h }}$ is the isotropic diffuse radiation on a horizontal surface in a free horizon at time $\mathrm{h} ; D_{\text {aniso_h }}$ is the anisotropic diffuse radiation on a horizontal surface in a free horizon at time $\mathrm{h} ; \Psi_{\text {svf }}$ is the SVF of the testing location. The $D_{\text {iso_h }}$ and $D_{\text {aniso_h }}$ are calculated with following equations:

$$
\begin{gathered}
D_{\text {iso_h }}=D_{0 \_\mathrm{h}} \times\left(1-\tau_{\mathrm{h}}\right) \\
D_{\text {iso_h }}=D_{0 \_\mathrm{h}} \times \tau_{\mathrm{h}} \\
\tau_{\mathrm{h}}=I_{0 \_\mathrm{h}} /\left(E_{0 \_\mathrm{h}} \cos \varphi_{\mathrm{h}}\right)
\end{gathered}
$$

where $D_{0_{-}} \mathrm{h}$ is the diffuse solar radiation at time $\mathrm{h}$ when there is no obstruction around, and this data is provided by the observation station; $\tau_{\mathrm{h}}$ is the transmittance of the direct solar radiation at time $\mathrm{h} ; E_{0 \_\mathrm{h}}$ is the extraterrestrial radiation at time $\mathrm{h} ; \varphi_{\mathrm{h}}$ is the sun zenith angle at time $\mathrm{h}$.

Total daily global solar radiation is calculated by adding up hourly values.

$$
G=\sum_{\mathrm{h}=\mathrm{h}_{0}}^{\mathrm{h}_{\mathrm{t}}}\left(I_{\mathrm{h}}+D_{\mathrm{h}}\right)
$$

where $G$ is total daily global solar radiation; $\mathrm{h}_{\mathrm{t}}$ is the sunset time; $h_{0}$ is the sunrise time.

\subsubsection{The method-two}

According to Li's method, the calculating only requires daily data of solar radiation.

The total daily direct solar radiation is calculated with following equation:

$$
I=I_{0} \times \frac{\sum_{\mathrm{h}=\mathrm{h}_{0}}^{\mathrm{h}_{\mathrm{h}}} f_{\mathrm{h}} \cdot \cos \varphi_{\mathrm{h}}}{\sum_{\mathrm{h}=\mathrm{h}_{0}} \cos \varphi_{\mathrm{h}}}
$$

where $I$ is the total daily direct solar radiation; $I_{0}$ is the total daily direct solar radiation when there is no obstruction around, provided by the observation station; the other variables have the same meaning as Eq. 1- Eq. 7.

The total daily diffuse solar radiation is calculated with following equation:

$$
D=D_{0} \times \Psi_{s v f}
$$

where $D$ is the total daily diffuse solar radiation; $D_{0}$ is the total daily diffuse solar radiation when there is no obstruction around, provided by the observation station; $\Psi_{\text {svf }}$ is the SVF of the testing location.

Total daily global solar radiation is calculated by adding total daily direct and diffuse solar radiation:

$$
G=I+D
$$

\section{Results and discussion}

\subsection{The comparison of calculations using two methods and testing results}

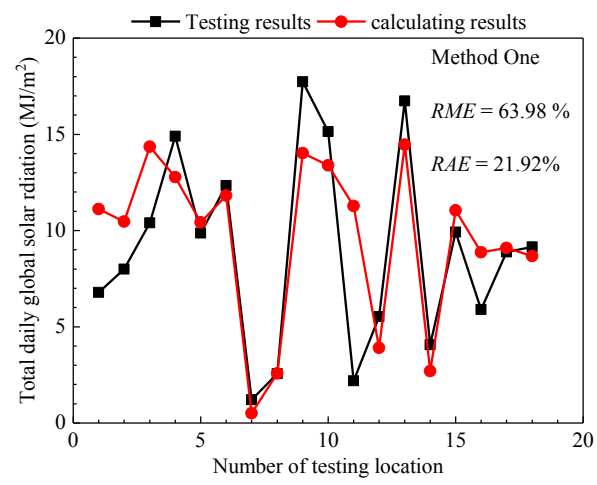

(a)

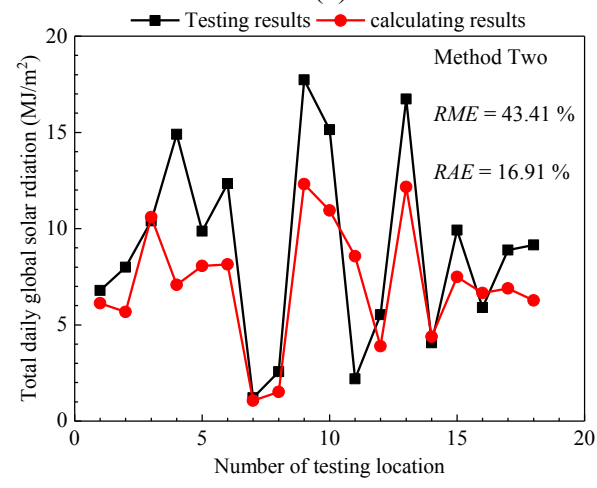

(b)

Fig. 5. Comparisons of calculations and testing results: (a) Method-one; (b) Method-two 
The calculated values of two methods both have the results matching the testing results or not (Fig. 5).

To evaluate the difference between calculations and testing results, relative maximum error $(R M E)$ and relative average error ( $R A E)$ are applied (Eq. 11 and Eq. 12). Since the $R M E$ and $R A E$ of method-one are both larger than method-two (Fig. 5), method-two seems more accurate.

$$
\begin{gathered}
R M E=\operatorname{Max}\left\{\left|\frac{x_{\mathrm{cac}}-x_{\mathrm{exm}}}{x_{\mathrm{exm}}}\right| \times 100 \%\right\} \\
R A E=\text { Average }\left\{\left|\frac{x_{\mathrm{cac}}-x_{\mathrm{exm}}}{x_{\mathrm{exm}}}\right| \times 100 \%\right\}
\end{gathered}
$$

where $x_{\text {cac }}$ is calculation and $x_{\text {exm }}$ is testing result.

In order to further analyse the applicability of the two methods, this paper use TVF to classify the locations. The relationships between TVF and relative difference $(R D)$ of the methods are investigated.

Relative difference $(R D)$ reflects the difference between the calculations and testing results. It can be used to judge the applicability of the two methods. $R D$ is calculated with following equation:

$$
R D=\frac{\left|x_{\mathrm{cac} 1}-x_{\mathrm{exm}}\right|-\left|x_{\mathrm{cac} 2}-x_{\mathrm{exm}}\right|}{x_{\mathrm{exm}}}
$$

where $x_{\text {cac1 }}$ is the calculation of method-one; $x_{\text {cac2 }}$ is the calculation of method-two; $x_{\text {exm }}$ is the testing result. If $R D>0$, then the method-two is more accurate, otherwise the method-one is more accurate.

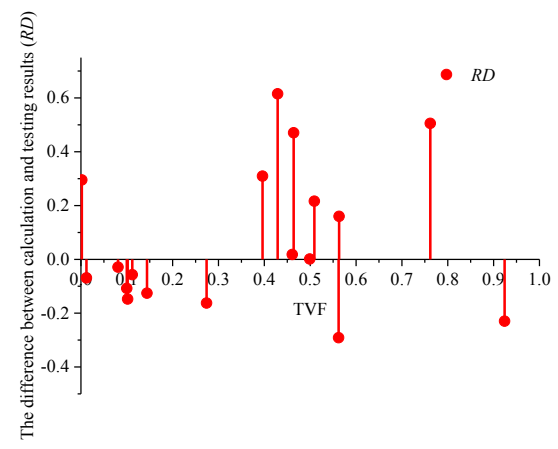

Fig. 6. Relationship between RD and TVF

When TVF is more than about 0.3 , method-two is more accurate than method-one generally (Fig. 6). The classifications of TVF and applicability of locations are shown in table 2 .

Table 2. Classify of results and locations

\begin{tabular}{|c|c|}
\hline Classification Standard & Locations \\
\hline $\begin{array}{c}\text { Results more accurate } \\
\text { when applied method-one }\end{array}$ & $\mathbf{0 4} 0506 \mathbf{0 8} 0910131718$ \\
\hline $\begin{array}{c}\text { Results More accurate } \\
\text { when applied method-two }\end{array}$ & $01020307 \mathbf{1 1} 12141516$ \\
\hline TVF $>0.3$ & $010203 \mathbf{0 4} 07 \mathbf{0 8 1 1} 121516$ \\
\hline TVF $\leq 0.3$ & $0506091013 \mathbf{1 4} 1718$ \\
\hline
\end{tabular}

After analysing the conditions of the locations with the panorama photos, some situations are noticed:

(1) The conditions of location 08, 11 and 14 have changed a lot since the time panorama photos were taken.
(2) Though the location 04 has a lot of trees in the photo, behind these tree area are almost full of the buildings. That is why the method-one is more accurate in this TVF $>0.3$ condition.

After rejecting the locations which have changed a lot, and considering the present conditions of the locations, this study further investigated the patterns SVF and TVF affecting the accuracy of two methods respectively.

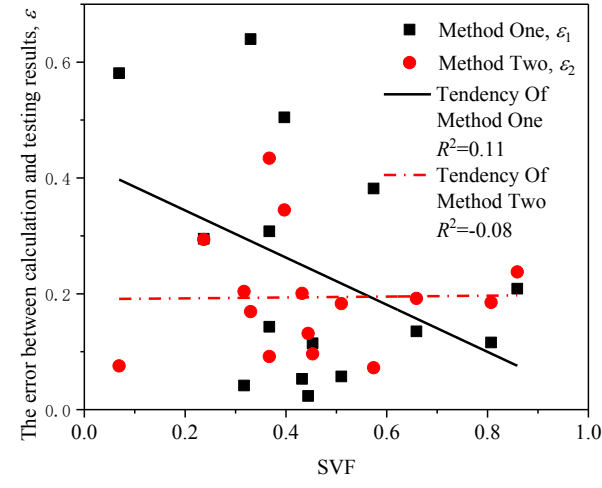

Fig. 7. Relationship between Error and SVF

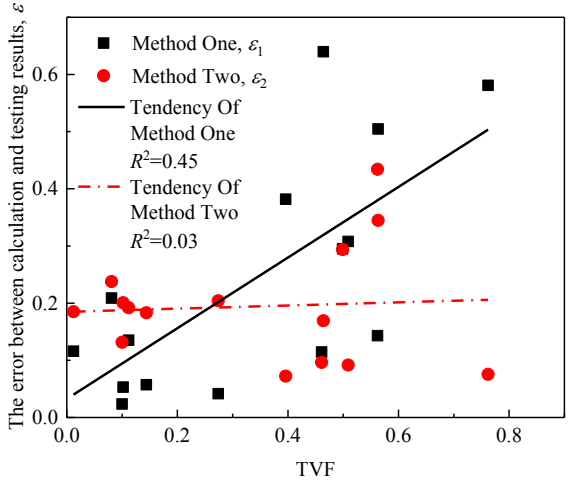

Fig. 8. Relationship between Error and TVF

Error $(\varepsilon)$ is the difference value between calculation and testing result. Calculated with following equations:

$$
\varepsilon=\frac{\left|x_{\mathrm{cac}}-x_{\mathrm{exm}}\right|}{x_{\mathrm{exm}}}
$$

The error of method-one decreases with the increasing of SVF and decreasing of TVF. While the accuracy of method-two almost has no change when SVF and TVF change. The correlation $\left(R^{2}\right)$ of TVF with the error of method-one $\left(R^{2}=0.45\right.$, Fig. 7) is much larger than the correlation $\left(R^{2}\right)$ of SVF with the error of method-one $\left(R^{2}=0.11\right.$, Fig. 7). Therefore, TVF affects the accuracy of the method more than SVF. The value of TVF is the basic standard to choose the methods.

With the increasing of TVF, the error of method-one increases, and method-two hardly changes. Besides, the two fitting lines of methods errors with TVF intersect at about TVF $=0.3$. Thus, with the increasing of TVF, the accuracy of method-one decreases, and method-two is hardly effected. When TVF $<0.3$, the accuracy of method-one is larger than method-two. When TVF $>0.3$, the accuracy of method-two will be larger than methodone, so that when TVF $>0.3$, the method-two should be chosen. 
The reason cause these results, may be the shapes of trees are not as clearer as buildings. When the sun blocked or not is judged, the buildings can block the direct solar radiation more entirely. Based on the calculation principle, method-one requires more clearly shape of obstruction. That is why the more trees around, the less accuracy method-one is.

\subsection{The comparison of calculations using two methods and testing results after screening and optimizing}

After combining the different methods based on the value of TVF of every location, the accuracy of calculations has a great improvement than before (Fig. 10).

The $R E M$ and $R A M$ both reduce a lot after combining the different methods (Table 3 ). This shows that combing the method-one and method-two to improve the accuracy of calculations is effective.

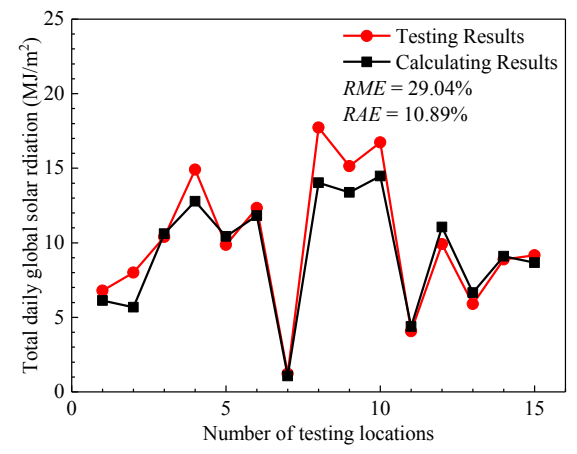

Fig. 10. Difference between calculations with testing results, after combining the method one and two

Table 3. Comparison of results

\begin{tabular}{|c|c|c|}
\hline Method & $\boldsymbol{R M E}$ & $\boldsymbol{R} \boldsymbol{A} \boldsymbol{E}$ \\
\hline 1 & $63.98 \%$ & $21.92 \%$ \\
\hline 2 & $43.41 \%$ & $16.91 \%$ \\
\hline $1-2$ & $29.04 \%$ & $10.89 \%$ \\
\hline
\end{tabular}

\section{Conclusions}

SVF and TVF are the parameters both affecting the solar radiation distribution rule in urban street. TVF also effects the accuracy of methods estimating the solar radiation. After testing and analysing, this study figures out the method suggested by Matzarakis is more suitable for the location with less trees around (TVF $<0.3)$, and the method suggested by $\mathrm{Li}$ is more suitable for the location with more trees around (TVF $>0.3$ ). When estimating the solar radiation, people should apply the appropriate methods.

In the future study, the patterns of street morphological characteristics and SVF affecting solar radiation can be further researched.

\section{Acknowledgement}

This work was supported by Natural Science Foundation of China (No. 51838011 and No. 51808429) and Young
Elite Scientists Sponsorship Program by CAST, YESS (No. 2018QNRC001).

\section{References}

1. T.R. Oke, Prog. Phys. Geogr, Earth Environ. 12, 471508 (1988).

2. T. Stathopoulos, H. Wu, J. Zacharias, Build. Environ. 39, 297-305 (2004).

3. L. E. Rhodes, A. R. Webb, H. I. Fraser, R. Kift, M.T. Durkin, D. Allan, S.J. O’Brien, A. Vail, J.L.Berry, J. Invest. Dermatol. 130, 1411-1418 (2010).

4. A. Calcabrini, H. Ziar, O. Isabella, M. Zeman, Nat. Energy. (2019).

5. S. Achour-Younsi, F. Kharrat, Tunisia, Procedia Soc. Behav. Sci. 216, 689-700 (2016).

6. J.A. Rodríguez Algeciras, L. Gómez Consuegra, A. Matzarakis, Build. Environ. 101, 85-101 (2016).

7. F. Bourbia, H.B. Awbi, F. Bourbia, H.B. Awbi, Renew. Energy. 29, 291-301 (2004).

8. T.P. Lin, A. Matzarakis, R.L. Hwang, Build. Environ. 45, 213-221 (2010).

9. M.K. Svensson, Meteorol. Appl. 11, 201-211 (2004).

10. E.L. Krüger, F.O. Minella, F. Rasia, Build. Environ. 46, 621-634 (2011).

11. I. D. Watson, G. T. Johnson, Int. J. Climatol. 7, 193197 (1987).

12. M.J. Brown, S. Grimmond, C. Ratti, Proc. 2001 Int. Symp. Environ. Hydraul. (2001).

13. R. Perze, R. Seals, P. Ineichen, R. Stewart, D. Menicucci, Sol. Energy. 39, 221-231 (1987).

14. T.R. OKE, Int. J. Climatol. 1, 237-254 (1981).

15. L. Zeng, J. Lu, W. Li, Y. Li, Build. Environ. 135, 7484 (2018).

16. F. Gong, Z Zeng, E. Ng, L.K. Norford, Build. Environ. 148, (2018).

17. F. Gong, Z. Zeng, F. Zhang, X. Li, E. Ng, L.K. Norford, Build. Environ. 134, 155-167 (2018).

18. X. Li, C. Ratti, Landscape. Urban. Plan. (2018).

19. X. Li, C. Ratti, Urban. For. Urban. Green. (2018).

20. A. Matzarakis, F. Rutz, H. Mayer, Int. J. Biometeorol. 54, 131-139 (2010).

21. A. Matzarakis, F. Rutz, H. Mayer, Int. J. Biometeorol. 51, 323-334 (2007).

22. R.L. Hwang, T.P. Lin, A. Matzarakis, Build. Environ. 46, 863-870 (2011)..

23. A. Matzarakis, O. Matuschek, Meteorol. Z. 20, 39-45 (2011).

24. T. Gál, F. Lindberg, J. Unger, Theor. Appl. Climatol. 95, 111-123 (2009).

25. C. Ratti, P. Richens, Theor. Appl. Climatol. 84, 7790 (2006).

26. D.G. Steyn, Atmos. Ocean. 18, 245-258 (1980). 
27. M. Hämmerle, T. Gál, J. Unger, A. Matzarakis, Theor. Appl. Climatol. 105, 521-527 (2011).

28. Baidu Street View API, (n.d.). http://lbsyun.baidu.com/index.php?title=static (Accessed July 20, 2019). 